\section{BMJ Paediatrics Open}

\title{
Paediatric dilated cardiomyopathy in Khartoum state, Sudan: a prospective study
}

\author{
Osama Hafiz Elshazali (i) , ${ }^{1}$ Ekhlas Abdalla ${ }^{2}$
}

To cite: Elshazali $\mathrm{OH}$, Abdalla E. Paediatric dilated cardiomyopathy in Khartoum state, Sudan: a prospective study. BMJ Paediatrics Open 2021;5:e000970. doi:10.1136/ bmjpo-2020-000970

Received 30 November 2020 Revised 23 March 2021 Accepted 5 April 2021
Check for updates

(c) Author(s) (or their employer(s)) 2021. Re-use permitted under CC BY-NC. No commercial re-use. See rights and permissions. Published by BMJ.

${ }^{1}$ Department of Paediatrics and Child Health, University of Khartoum Faculty of Medicine, Khartoum, Sudan

${ }^{2}$ Ahmed Gasim Paediatric Hospital, Khartoum North, Khartoum, Sudan

Correspondence to Dr Osama Hafiz Elshazali; 0. elshazali@uofk.edu

\section{ABSTRACT}

Background Dilated cardiomyopathy (DCM) is a disease of the heart muscle that affects ventricular function; it is a debilitating disease that can lead to heart failure and death in children. There is a lack of good epidemiological data about paediatric DCM in Sudan or in sub-Saharan Africa. Objective To study the incidence, causes and outcome of DCM among children in Sudan.

Methods A prospective cross-sectional study that was conducted in three paediatric hospitals in Khartoum state, Sudan over the period of 6 months.

Results During the study period, 55 children were seen with the diagnosis of DCM; The female: male ratio was 1.9:1. The incidence of DCM in Khartoum state was found to be 1.4 cases per 100000 children per year, 10 children $(18 \%)$ were diagnosed in the first year of their life. Twenty-seven children (49\%) showed evidence of failure to thrive, being below the fifth percentile for weight. The most common cause of DCM was found to be postviral in 27 children (49\%), followed by Idiopathic in 25 children $(45 \%)$. The most common presentation was the shortness of breath in 53 children (97\%), on echocardiography 26 children (47\%) showed evidence of severe left ventricular impairment and 23 children (42\%) showed moderate ventricular impairment. Regarding the outcome, 8 children (15\%) recovered, the condition of 11 children $(20 \%)$ remained static and there were 36 deaths (65\%).

Conclusion The incidence of DCM in Sudanese children was found to high with a higher mortality compared with middle-income and high-income countries; Improvement in the entire health system is needed to tackle this condition.

\section{INTRODUCTION}

Dilated cardiomyopathy (DCM) is a rare but debilitating disease of the heart that can lead to heart failure in both children and adults; DCM is a leading indication for cardiac transplantation in children and adults. ${ }^{1}$

DCM is characterised by ventricular chamber enlargement and systolic dysfunction. Diagnosis is usually made by twodimensional echocardiography. DCM leads to progressive heart failure and a decline in left ventricular contractile function; complications include ventricular and supraventricular arrhythmias, conduction system abnormalities, thromboembolism and heart

\section{What is known about the subject?}

- The majority of the data about paediatric dilated cardiomyopathy (DCM) came from high-income countries; this research attempts to provide insight about the incidence, prevalence, causes and the outcome of paediatric DCM in Khartoum state, Sudan.

\section{What this study adds}

- The incidence of paediatric DCM in Sudan is higher than that of high-income countries, the disease has a high morbidity and mortality, presents with severe symptoms and severely impaired ventricular function. This research will increase the awareness of this debilitating and fatal condition in low-income countries.

failure-related death. For children with DCM, the prognosis is generally considered as poor; approximately $40 \%$ of children undergo cardiac transplantation or die within 5 years of being diagnosed with DCM. ${ }^{2}$

The prognosis of paediatric DCM depends on their age at presentation and heart failure status.

Older age, more advanced heart failure symptoms and signs and worse ventricular function are associated with worse outcomes. ${ }^{13}$ Idiopathic DCM diagnosed after 6 years of age has an incidence of death or transplantation that is three to four times that of children diagnosed before the age of 6 years. ${ }^{4}$ Familial DCM account for $30 \%-35 \%$ of the cases of DCM. ${ }^{56}$

There is no reliable epidemiological data from Africa about Paediatric DCM, ${ }^{7}$ as such there is no epidemiological data about paediatric DCM in Sudan or the clinical course of the disease.

\section{Objective}

To study the incidence, causes and outcome of DCM among children in Khartoum state, Sudan. 


\section{MATERIAL AND METHODS}

\section{Patient and public involvement}

Patients were not involved in the design, recruitment and conduct of the study

\section{Study design}

This is prospective cross-sectional multicentre-based study; The study was conducted in Ahmed Gasim Paediatric hospital, Omdurman Paediatric hospital and Gaffar Ibn Ouf Paediatric hospital. These three hospitals are the largest and busiest children hospitals in Khartoum state and the country. The three hospitals cover all the cardiac referrals from Khartoum state and receive tertiary referral from the rest of country. Khartoum state has three cities, Khartoum, Omdurman and Khartoum North, Gaffar Ibn Ouf hospital is in Khartoum, Ahmed Gasim is in Khartoum North and Omdurman hospital is in Omdurman. The paediatric cardiac services are very limited outside of Khartoum state so the majority of the cardiac cases come to Khartoum state. The study was conducted over a 6-month period from December 2018 to May 2019.

\section{Study population and sample size}

Inclusion criteria: All of the children up to the age of 18 years with DCM who were either admitted or seen in the outpatient clinics during the study period in any of the three hospitals were included in the study.

Exclusion criteria: Children with DCM and any other known cardiac diagnosis were excluded from the study such as congenital heart disease, rheumatic heart disease. All of the children who presented with DCM were included rather than taking a sample from them as we expected that the number would be few.

Children were labelled to have DCM if they have symptoms of unexplained heart failure and echocardiography shows the characteristics features of ventricular chamber enlargement and systolic dysfunction with normal left ventricle (LV) wall thickness. ${ }^{15}$

For the study, fractional shortening (FS) was used to assess ventricular function, FS is calculated using the following equation: FS=LVIDd - LVIDs/LVIDd $\times 100 \%$.

Where, LVIDd=LV internal diameter at end diastole and LVIDs $=\mathrm{LV}$ internal diameter at end systole. ${ }^{89}$ Ventricular dysfunction was characterised as severe (FS less than $14 \%$ ), moderate (FS 15\%-19\%) and mild (FS 20\%-24\%).

Aetiology of DCM was characterised mainly based on family history and clinical diagnosis as advanced investigations for DCM such as genetic testing, metabolic and advanced virology studies are not available in Sudan.

\section{Data collection}

The data were collected from hospital files and personal interviews with the parents using a pretested questionnaire and a check list.

The questionnaire included demographic data such as age, residence, consanguinity and clinical data such as presentation, investigations, final diagnosis, treatment and outcome. Anthropometric measurements were referenced using WHO percentile growth charts.

A written consent was taken from all of the parents, it was made very clear to the parents that participation is voluntary and that they could withdraw from the study at any stage without affecting the management of their children. The study questionnaires were coded to protect the patients' confidentiality and privacy.

\section{RESULTS}

This study included 55 children with the diagnosis of DCM, there were 36 females (65\%) and 19 males (35\%), with a female: male ratio of 1.9:1. Thirty two of the children $(58 \%)$ were residents in Khartoum state and 23 $(42 \%)$ were from other states. Twenty-eight children were newly diagnosed with DCM while 27 were known to have DCM and on regular follow-up.

From the 32 children from Khartoum state, 18 were newly diagnosed cases of DCM. The population of children in Khartoum state is $2523980,{ }^{10}$ this gives a prevalence of 1.3 cases per 100000 children, an incidence of 0.7 cases per 100000 children over 6 months and an incidence of 1.4 cases per 100000 children per year in Khartoum state.

The age of the children ranged from 2 months to 17 years; the mean age was $7.5 \pm 5.4$ years; the age at diagnosis ranged from 1 month to 17 years; mean age of diagnosis was $7.0 \pm 5.5$ years.

The mean duration of follow-up after diagnosis for the 27 children who were known to have DCM was $1.2 \pm 1.2$ years; The most common age group at diagnosis was $10-18$ years old with 19 children $(35 \%)$, only 10 children $(18 \%)$ were diagnosed less than 1 year of age (figure 1$)$.

The most common presentation was the shortness of breath in 53 children (97\%) followed by cough and irritability in 50 children $(91 \%)$ (table 1 ).

The children presented with a severe spectrum of the disease with 42 children (76\%) in Ross functional class 4 and 13 children $(24 \%)$ in Ross functional class $3 .{ }^{11}$ There

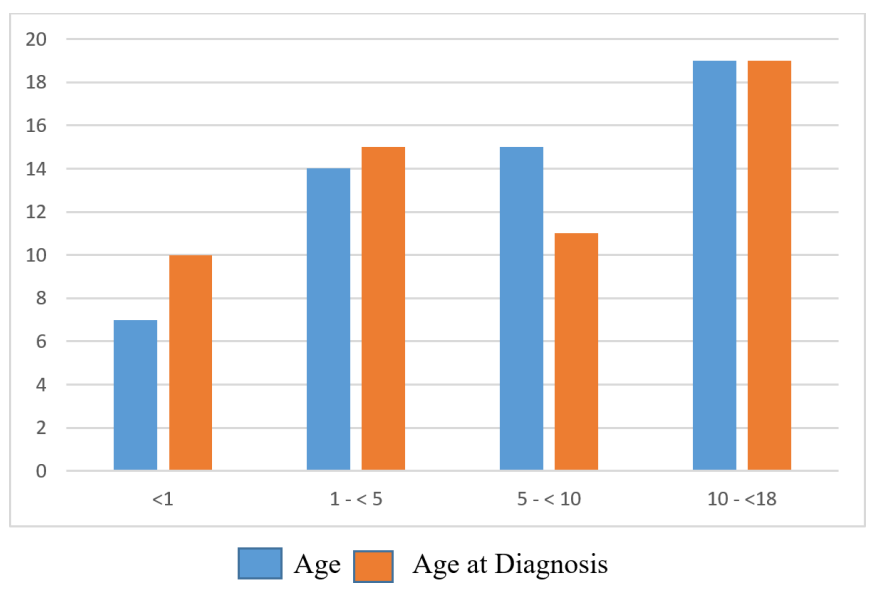

Figure 1 Age frequency distribution. 
Table 1 Clinical presentation $(n=55)$

\begin{tabular}{llll}
\hline & & Frequency & Per cent \\
\hline & $\begin{array}{l}\text { Shortness of } \\
\text { breaths }\end{array}$ & 53 & 97 \\
Presenting & Cough & 50 & 91 \\
symptoms and & Irritability & 50 & 91 \\
& Palpitations & 27 & 49 \\
& Pallor & 19 & 35 \\
& Oedema & 12 & 22 \\
& Chest pain & 11 & 20 \\
& Orthopnoea & 11 & 20 \\
& Sweating & 8 & 15 \\
& Syncope & 1 & 2 \\
\hline
\end{tabular}

were 27 children (49\%) with severe growth retardation with their weight below the fifth percentile.

Echocardiography showed 26 children (47\%) to have severe ventricular dysfunction, 23 children (42\%) to have moderate ventricular dysfunction and six children $(11 \%)$ to have mild ventricular dysfunction.

The study found that 27 children (49\%) were diagnosed with post viral DCM, 25 children (45\%) were diagnosed with idiopathic DCM and 3 children $(6 \%)$ were diagnosed with familial DCM. For the three children with a family history of DCM, all of them had a death of at least one of their siblings in the first 1-2 years of life due to DCM. We have investigated all of the parents and siblings of the three children using echocardiography and found that only one of the sibling was found to have DCM.

This study reported that all of the children received furosemide and the majority had also received aspirin, captopril, carvedilol and spironolactone (table 2). Three children were admitted to the ICU and had received inotropic and ventilator support; all three of them died.

There were 36 deaths $(65 \%), 8(15 \%)$ children recovered and $11(20 \%)$ children continued to have residual disease (table 3 ). There was no difference in mortality according to the aetiology.

\begin{tabular}{llll}
\hline Table 2 & Drug treatment $(\mathrm{n}=55)$ & & \\
\hline \multirow{3}{*}{ Medication } & Frequency & Per cent \\
& Furosemide & 55 & 100 \\
& Aspirin & 54 & 99 \\
& Captopril & 53 & 97 \\
& Spironolactone & 50 & 91 \\
& Carvedilol & 50 & 91 \\
& L-carnitine & 29 & 53 \\
& Dopamine & 3 & 6 \\
& Digoxin & 1 & 2 \\
\hline
\end{tabular}

\section{DISCUSSION}

The study identified 55 children with DCM in the three hospitals during the study period, during the same period, there were 5534 paediatric admissions and outpatient reviews.

A large scale national study from Finland ${ }^{12}$ showed the incidence of Paediatric DCM to be 0.34 cases per 100000 children per year and a prevalence of 2.6 cases per 100000 children. Two large scale studies from the Paediatric Cardiomyopathy Registry in USA reported the incidence of Paediatric DCM to be 0.57 cases per 100000 per year. ${ }^{36}$ Another large study from the USA ${ }^{2}$ showed an incidence of 0.58 cases per 100000 per year. In all of these studies the incidence was higher in males compared with females, in blacks compared with whites and in infants compared with older children.

Our study showed that the incidence of DCM in Sudanese children is high when compared with other countries. We believe that the figures we have for the incidence and prevalence rate are approximates and are underestimates of the true figure as not all the children with DCM in Khartoum state would have been able to make it to the tertiary hospitals due to misdiagnosis at the primary or secondary level, never the less the figure provided that is theorised to be underestimate is still relatively high compared with the figures reported from the high-income countries.

The prevalence in our study is equal to the incidence over 1 year, this could be explained by the high mortality and poor survival, the mortality rate in the study was high at $65 \%$ and the mean follow-up period of children known to have DCM was relatively short at 1.2 years indicating poor survival.

In the study, the female to male ratio was 1.9:1, largescale studies from the USA ${ }^{26}$ showed that DCM was more common in males, however, two different studies from Saudi Arabia showed DCM to be more common in females with a female to male ratio of $1.8: 1$ in both studies. ${ }^{1314}$ This difference in prevalence of DCM according to gender in different populations could be related to the prevalence of some sex-linked recessive diseases in the population like Duchene and Becker Muscular dystrophy. ${ }^{15}$

The most common age of presentation of DCM in the study was more than 10 years old with 19 children (35\%) and only $10(18 \%)$ children were diagnosed within the first year of life (figure 1), this is in contrast to studies from other parts of the world which showed that the majority of children presented during the first year of age $\mathrm{e}^{61316}$; a later age of presentation was one of the factors that is associated with a worse prognosis. ${ }^{46912}$

In Khartoum state, the rate of severe growth retardation in children is $6.6 \%{ }^{17}$; in our study, twenty seven children $(49 \%)$ had severe growth retardation, this finding indicates that DCM in Sudanese children is associated with failure to thrive $(p=0.01)$. Previous studies have shown that growth impairment in children with DCM was associated with heart failure and more than double the 
Table 3 The relationship between age at diagnosis and the outcome $(n=55)$

\begin{tabular}{|c|c|c|c|c|}
\hline \multirow[b]{2}{*}{ Age at diagnosis in years } & \multirow[t]{2}{*}{ Frequency } & \multicolumn{3}{|l|}{ Outcome } \\
\hline & & Improved & Static & Death \\
\hline$<1$ & $\begin{array}{l}10 \\
(18 \%)\end{array}$ & $3(30 \%)$ & $4(40 \%)$ & $3(30 \%)$ \\
\hline 1 to $<5$ & $\begin{array}{l}15 \\
(27 \%)\end{array}$ & $3(20 \%)$ & $0(0 \%)$ & $12(80 \%)$ \\
\hline 5 to $<10$ & $\begin{array}{l}11 \\
(20 \%)\end{array}$ & $2(18 \%)$ & $3(27 \%)$ & $6(55 \%)$ \\
\hline $10-18$ & $\begin{array}{l}19 \\
(35 \%)\end{array}$ & $0(0 \%)$ & $4(21 \%)$ & $15(79 \%)$ \\
\hline Total & 55 & $8(15 \%)$ & 11 (20\%) & 36 (65\%) \\
\hline
\end{tabular}

risk of death compared with DCM children with normal weight. ${ }^{1819}$

In the study, 53 children (97\%) presented with symptoms of heart failure (table 1), this figure is much higher than the figure of $70 \%-74 \%$ reported by studies from other parts of the world. ${ }^{6}{ }^{13} 16$ All of the children presented with severe symptoms with 42 children $(76 \%)$ in Ross class 4 and the rest in Ross class 3. Likewise, echocardiography showed the majority of children to have moderate to severe left ventricular impairment.

Regarding the aetiology of DCM, the most common causes was post viral in 27 children (49\%) and idiopathic in 25 children $(45 \%)$. In the USA, the most common cause of DCM was idiopathic in $66 \%$, followed by postviral in $16 \%{ }^{6}$

In Sudan, we do not have most of the investigations to determine the cause of DCM such as genetic, advanced metabolic and viral studies; the majority of the parents cannot afford the cost of sending such investigations abroad. The diagnosis of postviral DCM in the study was mainly clinical with no supporting virology studies in the majority of cases; The lack of diagnostic investigations is one of the main challenges of management of DCM in the low resources' setting.

In high-income countries, familial DCM is known to be the cause of DCM in $20 \%-35 \% .^{5}$

In the study, only three children $(6 \%)$ had a family history of DCM, with a sibling death in all the three families. it is our belief that the figure of $6 \%$ is an underestimate as we do not have the facility for genetic testing in Sudan; in addition, a proportion of cardiomyopathy cases will be misdiagnosed and labelled as another diagnosis such as pneumonia or asthma and this would be missed in the family history.

In the study, 36 children $(65 \%)$ died. A large study from that USA showed that freedom from death or transplantation was $69 \%$ at 1 year, $61 \%$ at 2 years, $54 \%$ at 5 years and $46 \%$ at 10 years. ${ }^{6}$ A study from Turkey found the mortality to be $5 \%,{ }^{16}$ a Saudi study reported that the survival rate over 3 years was $78 \%{ }^{13}$ and in Colombia, the mortality rate was $29.4 \% .{ }^{20}$ Compared with the published literature, it is clear that the mortality in the Sudanese population is relatively high.

Similar to many other low income countries Sudan has a scarce availability of Paediatric intensive care services and no heart transplantation programme; both of these factors contribute to mortality. Children with the severe form of DCM needs intensive and specialised care, in Khartoum state there are only 20 Paediatric ICU beds, children population in Khartoum is $2523980 .{ }^{10}$

\section{Limitations}

This is a hospital-based study so the children seen will tend to have a severe illness; in order to balance this, we had included children with DCM whom were seen in the outpatients' clinics, they tend to have a milder form of the disease. It would have been ideal if the duration of the study was for 1 year, however, for practical reasons, only 6 months were possible.

In Sudan, we do not have the facility of genetic testing as well as advanced viral studies hence the diagnosis of viral cardiomyopathy was mainly a clinical diagnosis.

\section{CONCLUSION}

The study showed that the incidence of DCM is relatively high in comparison to the middle-income and high-income countries. The mortality rate is also high as compared with paediatric DCM patients in middleincome and high-income countries. Improvement in the health system as a whole is needed to tackle this condition, through developing the capacity for appropriate clinical services at primary, secondary and tertiary levels.

Contributors OHE and EA conceived, planned and carried the research. OHE took the lead in writing the manuscript. Both authors were involved in the designing, planning, conducting and writing the study.

Funding The authors have not declared a specific grant for this research from any funding agency in the public, commercial or not-for-profit sectors.

Competing interests None declared.

Patient and public involvement Patients and/or the public were not involved in the design, or conduct, or reporting, or dissemination plans of this research. 
Patient consent for publication Not required.

Ethics approval Ethical approval was obtained from Sudan Medical Specialisation Board Research and Ethics committee: ID SMSB-2018-246.

Provenance and peer review Not commissioned; externally peer reviewed.

Data availability statement All data relevant to the study are included in the article or uploaded as online supplemental information. All data relevant to the study are included in the article.

Open access This is an open access article distributed in accordance with the Creative Commons Attribution Non Commercial (CC BY-NC 4.0) license, which permits others to distribute, remix, adapt, build upon this work non-commercially, and license their derivative works on different terms, provided the original work is properly cited, appropriate credit is given, any changes made indicated, and the use is non-commercial. See: http://creativecommons.org/licenses/by-nc/4.0/.

ORCID iD

Osama Hafiz Elshazali http://orcid.org/0000-0002-8528-4051

\section{REFERENCES}

1 Lipshultz SE, Cochran TR, Briston DA, et al. Pediatric cardiomyopathies: causes, epidemiology, clinical course, preventive strategies and therapies. Future Cardiol 2013;9:817-48.

2 Lipshultz SE, Sleeper LA, Towbin JA, et al. The incidence of pediatric cardiomyopathy in two regions of the United States. N Engl J Med 2003;348:1647-55.

3 Wilkinson JD, Sleeper LA, Alvarez JA, et al. The pediatric cardiomyopathy registry: 1995-2007. Prog Pediatr Cardiol 2008;25:31-6.

4 Alvarez JA, Orav EJ, Wilkinson JD, et al. Competing risks for death and cardiac transplantation in children with dilated cardiomyopathy. Circulation 2011;124:814-23.

5 Maron BJ, Towbin JA, Thiene G, et al. Contemporary definitions and classification of the cardiomyopathies: an American heart association scientific statement from the Council on clinical cardiology, heart failure and transplantation Committee; quality of care and outcomes research and functional genomics and translational biology interdisciplinary working groups; and Counci on epidemiology and prevention. Circulation 2006;113:1807-16.
6 Towbin JA, Lowe AM, Colan SD, et al. Incidence, causes, and outcomes of dilated cardiomyopathy in children. JAMA 2006;296:1867-76

7 Brink AJ, Aalbers J. Strategies for heart disease in sub-Saharan Africa. Heart 2009;95:1559-60.

8 Lang RM, Badano LP, Mor-Avi V, et al. Recommendations for cardiac chamber quantification by echocardiography in adults: an update from the American Society of echocardiography and the European association of cardiovascular imaging. J Am Soc Echocardiogr 2015;28:1-39.

9 Chengode S. Left ventricular global systolic function assessment by echocardiography. Ann Card Anaesth 2016;19:26-34.

10 Khartoum (state) - Wikipedia [Internet]. Available: https://en. wikipedia.org/wiki/Khartoum (state) [Accessed 7 Oct 2020].

11 Ross RD, Bollinger RO, Pinsky WW. Grading the severity of congestive heart failure in infants. Pediatr Cardiol 1992;13:72-5.

12 Arola A, Jokinen E, Ruuskanen O, et al. Epidemiology of idiopathic cardiomyopathies in children and adolescents. A nationwide study in Finland. Am J Epidemiol 1997;146:385-93.

13 Azhar AS. Pediatric idiopathic dilated cardiomyopathy: a single center experience. J Nat Sci Biol Med 2013;4:145-8.

14 Saad IA. Idiopathic dilated cardiomyopathy in children: natural history and predictors of prognosis. Libyan J Med 2007;2:129-34.

15 Connuck DM, Sleeper LA, Colan SD, et al. Characteristics and outcomes of cardiomyopathy in children with Duchenne or Becker muscular dystrophy: a comparative study from the pediatric cardiomyopathy registry. Am Heart J 2008;155:998-1005.

16 Bostan OM, Cil E. Dilated cardiomyopathy in childhood: prognostic features and outcome. Acta Cardiol 2006;61:169-74.

17 Musa TH, Musa HH, Ali EA, et al. Prevalence of malnutrition among children under five years old in Khartoum state, Sudan. Polish Annals of Medicine 2014;21:1-7.

18 Castleberry CD, Jefferies JL, Shi L, et al. No obesity paradox in pediatric patients with dilated cardiomyopathy. JACC Heart Fail 2018;6:222-30.

19 Lavie CJ, Ventura HO. Obesity and Prognosis in Pediatric Dilated Cardiomyopathy: No Paradox or Adverse Effects. JACC Heart Fail 2018;6:231-2.

20 Nogueira G, Pinto FF, Paixão A, et al. Idiopathic dilated cardiomyopathy in children: clinical profile and prognostic determinants. Rev Port Cardiol 2000;19:191-200. 